\title{
Collagen VI Is a Subepithelial Adhesive Target for Human Respiratory Tract Pathogens
}

\author{
Marta Bober Charlotte Enochsson Mattias Collin Matthias Mörgelin \\ Division of Infection Medicine, Department of Clinical Sciences, Biomedical Center, Lund University, Lund, Sweden
}

\section{Key Words}

Adhesin · Airways $\cdot$ Collagen VI · Host-pathogen

interaction • Primary adhesion • Respiratory infection •

Respiratory pathogen $\cdot$ Streptococcus

\begin{abstract}
Bacterial engagement of specific host tissue structures can be a means of targeting a pathogen to a particular niche, establishing persistent infections and inducing invasion. In this context, primary adhesion is often the first crucial colonization step allowing pathogens to withstand the mechanical clearing mechanisms of the host. As a consequence, bacteria have evolved adhesins with the capacity to mediate interaction between microorganism and host. Here we describe collagen VI as a novel target for adherence of Streptococcus pyogenes and Streptococcus pneumoniae. In upper and lower airways this collagen was distributed in the lamina propria underneath the epithelial basement membrane. Both pathogens exhibited strong affinity to collagen $\mathrm{VI}$ as shown by light and electron microscopy in combination with immunodetection and in vitro binding assays. For $S$. pyogenes this interaction was mediated by M1 protein. The presented data provide evidence for a previously unrecognized role for collagen VI in host-pathogen interplay during respiratory tract infection.

Copyright $\odot 2009$ S. Karger AG, Basel
\end{abstract}

(C) 2009 S. Karger AG, Basel

$1662-811 X / 10 / 0022-0160 \$ 26.00 / 0$

Fax +4161306 1234

E-Mail karger@karger.ch

www.karger.com
Accessible online at:

www.karger.com/jin

\section{Introduction}

The adherence of bacteria to host tissue is a primary crucial step in host targeting, colonization and development of disease. After entering the host, pathogens adhere to cell adhesion molecules by surface adhesins. Bacterial adhesins that interact with extracellular matrix components such as collagen I and IV, fibronectin and fibrinogen have been identified for both Gram-negative and Gram-positive bacteria [1-6].

Fibrillar collagens are the most abundant structural proteins in the body. They are characterized by a glycinerich triple helix which is composed of $3 \alpha$-chains that can either be identical (homotrimers) or differ in composition (heterotrimers) [7]. Collagens have been reported as adhesive substrates for a number of pathogenic bacteria and clinical isolates [8], and are considered important for a variety of diseases including septic arthritis, infective endocarditis, gingivitis, bacterial meningitis and pneumonia. Studies have so far been focused on the classical striated fibrillar collagen type I or the basement membrane collagen type IV [9]. This can be explained by the fact that these collagens are very abundant, but also by the sites of infection of these pathogens, like collagen type I-rich skin and bone tissues, and the observation that bacteria regularly overcome subepithelial barriers (i.e. the basement membrane) and cause deep tissue in-

Dr. Matthias Mörgelin

Department of Clinical Sciences

Biomedical Center, Floor B14, Lund University

Tornavägen 10, SE-22184 Lund (Sweden)

Tel. +46 46222 0741, Fax +46 46157 756, E-Mail matthias.morgelin@med.lu.se 
fections. In this work we therefore examine whether collagen type VI can be a target for microbial adherence. Collagen VI is a heterotrimer which is assembled into characteristic microfibrils and is thought to serve as an anchoring element between major fibrillar systems and basement membranes or cells $[10,11]$. It is genetically conserved between different vertebrate species and widely distributed in the body. In human and other vertebrates it is present in vascular walls and in the interstitial space of upper and lower airways [for references see 12]. Interestingly, collagen VI expression is upregulated in lung fibrosis and its expression level appears independent of the etiology of fibrosis [13].

Streptococcus pyogenes is a human pathogen that can cause a variety of diseases, ranging from mild and superficial infections, such as pharyngitis, to invasive and lifethreatening conditions, including necrotizing fasciitis and streptococcal toxic shock syndrome [14]. Serious sequelae are acute rheumatic fever and glomerulonephritis. Streptococcus pneumoniae is the most common pathogen associated with community-acquired respiratory tract infections and a leading causative agent in fatal cases of meningitis or bacteremia [15] This pathogen is responsible for most cases of pneumonia in children and frequently colonizes the lower airways of individuals suffering from respiratory disorders. In many healthy individuals $S$. pneumoniae is carried in the upper respiratory tract and the mechanisms by which the bacteria translocate to the lung are still elusive.

Susceptibility towards respiratory microbial infections varies within different diseases, a fact that is believed to be associated with the different pathophysiologies. Despite the clinical importance and the occasionally serious pathogenesis, molecular colonization mechanisms for these pathogens are still poorly understood. In this study we provide evidence that collagen VI is a substrate for common human lung pathogens with the potential to trigger streptococcal pathogenesis. Microbial adherence to this collagen is mediated by cyanogen bromide (CNBr)extractable surface adhesins, and for $S$. pyogenes we identified M1 protein as a novel collagen VI adhesin.

\section{Methods}

Bacterial Strains and Growth Conditions

Experiments were conducted with the following bacterial species and type strains: $S$. pyogenes strain AP1 of M1 serotype and S. pneumoniae strain PR 218 (capsulated). The strains were grown in Todd-Hewitt broth (Difco, Detroit, Mich., USA) at $37^{\circ} \mathrm{C}$ in a humid atmosphere containing $5 \% \mathrm{CO}_{2}$.

Collagen VI is a Target for Respiratory

Tract Pathogens

\section{Radiolabeling of Collagens}

Collagen I was purchased from Vitrogen (Fremont, Calif., USA) and collagen IV was obtained from Sigma (St. Louis, Mo., USA). Collagen type VI microfibrils were extracted from bovine cornea by limited collagenase digestion as described by Spissinger and Engel [16] with modifications as in Wiberg et al. [17]. Radiolabeling with ${ }^{125}$ Iodine was performed using IODO-BEADS (Pierce, Rockford, Ill., USA) according to the manufacturer's instructions in PBSAT buffer $(140 \mathrm{mM} \mathrm{NaCl}, 30 \mathrm{mM} \mathrm{KCl}, 8 \mathrm{~mm}$ $\mathrm{Na}_{2} \mathrm{HPO}_{4}, 2 \mathrm{mM} \mathrm{KH}_{2} \mathrm{PO}_{4}$ ) containing $0.05 \%$ Tween 20 and $0.02 \%$ sodium azide). For all experiments, the total radioactivity was adjusted to 10,000 counts per minute, corresponding to approximately 12.5 ng protein, by dilution with PBSAT.

\section{Collagen Binding Assays}

Overnight cultures of bacteria were washed 3 times with PBSAT and collected by centrifugation at $1,500 \mathrm{~g}$ for $10 \mathrm{~min}$. The amount of bacteria was adjusted to $2 \times 10^{9}$ colony forming units (cfu) per ml with PBSAT and $200 \mu \mathrm{l}$ of bacterial suspension was incubated with 10,000 counts per minute of $\left[{ }^{125} \mathrm{I}\right]$-collagen for 30 $\mathrm{min}$ at RT. Bacteria were serially diluted with PBSAT to $1 \%(2 \times$ $\left.10^{9} \mathrm{cfu} / \mathrm{ml}\right), 0.5 \%\left(1 \times 10^{9} \mathrm{cfu} / \mathrm{ml}\right), 0.1 \%\left(2 \times 10^{8} \mathrm{cfu} / \mathrm{ml}\right), 0.01 \%$ $\left(2 \times 10^{7} \mathrm{cfu} / \mathrm{ml}\right)$ and $0.001 \%\left(2 \times 10^{6} \mathrm{cfu} / \mathrm{ml}\right)$. PBSAT was used as a vehicle in control experiments. Finally, bacteria were collected by centrifugation at $1,500 \mathrm{~g}$ and the radioactivity of the pellet was determined. Experiments were carried out 5 times in triplicate.

\section{$\mathrm{CNBr}$ Treatment of Bacteria}

$\mathrm{CNBr}$ extraction of bacterial surface proteins was performed as previously described [18]. The cleaved surface proteins were radiolabeled with ${ }^{125}$ Iodine or conjugated with $15 \mathrm{~nm}$ colloidal gold after titration and stored in TBS at $4^{\circ} \mathrm{C}$ until further use.

Gold Labeling of Proteins and Bacterial Binding Assay

Collagens and the bacterial proteins $\mathrm{M} 1$ and $\mathrm{H}$ were conjugated with $5 \mathrm{~nm}$ colloidal gold particles after titration and stored in TBS at $4^{\circ} \mathrm{C}$. Solutions of bacteria (1\%, corresponding to $2 \times$ $10^{9} \mathrm{cfu} / \mathrm{ml}$ ) were mixed with equal amounts of gold conjugates $(10$ $\mathrm{mg} / \mathrm{ml})$ or unconjugated collagen VI microfibrils $(100 \mathrm{mg} / \mathrm{ml})$, allowed to react for $30 \mathrm{~min}$ at RT and negatively stained with uranyl formate prior to electron microscopy.

\section{Tissue Extraction and Ligand Blot}

Tissue components from murine pharynx and bronchi were extracted by boiling in $20 \%$ SDS for $20 \mathrm{~min}$. Solubilized proteins and purified collagen I and VI were separated by reducing SDSPAGE on a $3-12 \%$ gradient gel in the presence of $5 \% \beta$-mercaptoethanol and stained with Coomassie Brilliant Blue or electroblotted onto a PVDF membrane (Immobilon; Millipore). The membrane was washed twice for $30 \mathrm{~min}$ in blocking buffer (PBS containing $0.25 \%$ Tween 20 and $2 \%$ bovine serum albumin), incubated with ${ }^{125} \mathrm{I}$-radiolabeled $\mathrm{CNBr}$ extracts overnight at $4{ }^{\circ} \mathrm{C}$, and washed 3 times for $20 \mathrm{~min}$ in blocking buffer. Signals of bound ligand were detected using BAS1800 imaging plates (Fuji Film, Tokyo, Japan).

\section{Tissue Sample Processing and Immunohistochemistry}

Tissue samples from murine pharynx and bronchus were fixed in PBS containing $4 \%$ paraformaldehyde $+0.1 \%$ glutaraldehyde and prepared for light and electron microscopy as described [19].

J Innate Immun 2010;2:160-166 
Immunodetection of collagen VI was done by fluorescence microscopy using a polyclonal rabbit antibody (a kind gift of Dr. Rupert Timpl, Martinsried, Germany) and FITC-conjugated antirabbit IgG (Jackson ImmunoResearch, West Grove, Pa., USA) as secondary antibody. Visual inspection and recording of images were performed using a Nikon Eclipse TE300 inverted fluorescence microscope equipped with a Hamamatsu C4742-95 cooled CCD camera. Immunostaining and transmission electron microscopy were performed as described by Bengtson et al. [20]. In short, samples were incubated with the primary antibody and gold conjugated CNBr extracts (dilution 1:50-1:100), followed by detection with a secondary antibody (5 nm gold; Electron Microscopy Sciences, Fort Washington, Pa., USA; diluted 1:10-1:20). Specimens were examined in a JEOL JEM 1230 transmission electron microscope (JEOL, Peabody, Mass., USA) at $60 \mathrm{kV}$ accelerating voltage. Images were recorded with a Gatan Multiscan 791 CCD camera.

\section{Results and Discussion}

\section{Collagen VI Is Distributed Underneath the}

Respiratory Epithelium in the Upper and Lower

Airways and Is a Substrate for Streptococcal Adhesins

Immunohistochemistry on paraffin sections using a FITC-labeled collagen VI antibody identified the collagen (fig. 1a, d, arrows) in the subepithelial lamina propria in murine pharynx and bronchus. Similar observations were made by immunoelectron microscopy of tissue specimens using the same antibody and a secondary antibody conjugated with $5 \mathrm{~nm}$ gold. Collagen VI was distributed in close association with cross-striated collagen I fibrils distant to the epithelial basement membrane (fig. $1 \mathrm{~b}, \mathrm{c}, \mathrm{e}, \mathrm{f}$ ). $\mathrm{CNBr}$ extracted surface proteins from $S$. pyogenes (fig. 1b, e) and S. pneumoniae (fig. 1c, f), conjugated with $15 \mathrm{~nm}$ colloidal gold, were frequently observed co-localized with collagen VI.

Fig. 1. Collagen VI in upper and lower airways is a substrate for bacterial adhesins. a, d Immunohistochemistry demonstrating presence of collagen VI in pharyngeal (a) and bronchial (d) tissue sections. The epithelium (E) is located at the interphase between the airway lumen (L) and the underlying lamina propria (LP). Collagen VI is distributed in an intensely stained region (arrowheads) underneath the epithelial cells. Scale bar $=20 \mu \mathrm{m}$. b, c, e, f Immunogold electron microscopy and co-localization of collagen VI ( $5 \mathrm{~nm}$ gold particles) with bacterial adhesins ( $15 \mathrm{~nm}$ gold particles). Collagen VI is located between striated collagen I fibrils in the lamina propria and detected by a gold labeled antibody. $\mathrm{CNBr}$ extracted surface proteins of $S$. pyogenes $(\mathbf{b}, \mathbf{e})$ and $S$. pneumoniae $(\mathbf{c}, \mathbf{f})$ were directly conjugated with colloidal gold particles and are frequently co-localized with collagen VI (arrows). Scale bar $=100 \mathrm{~nm}$.
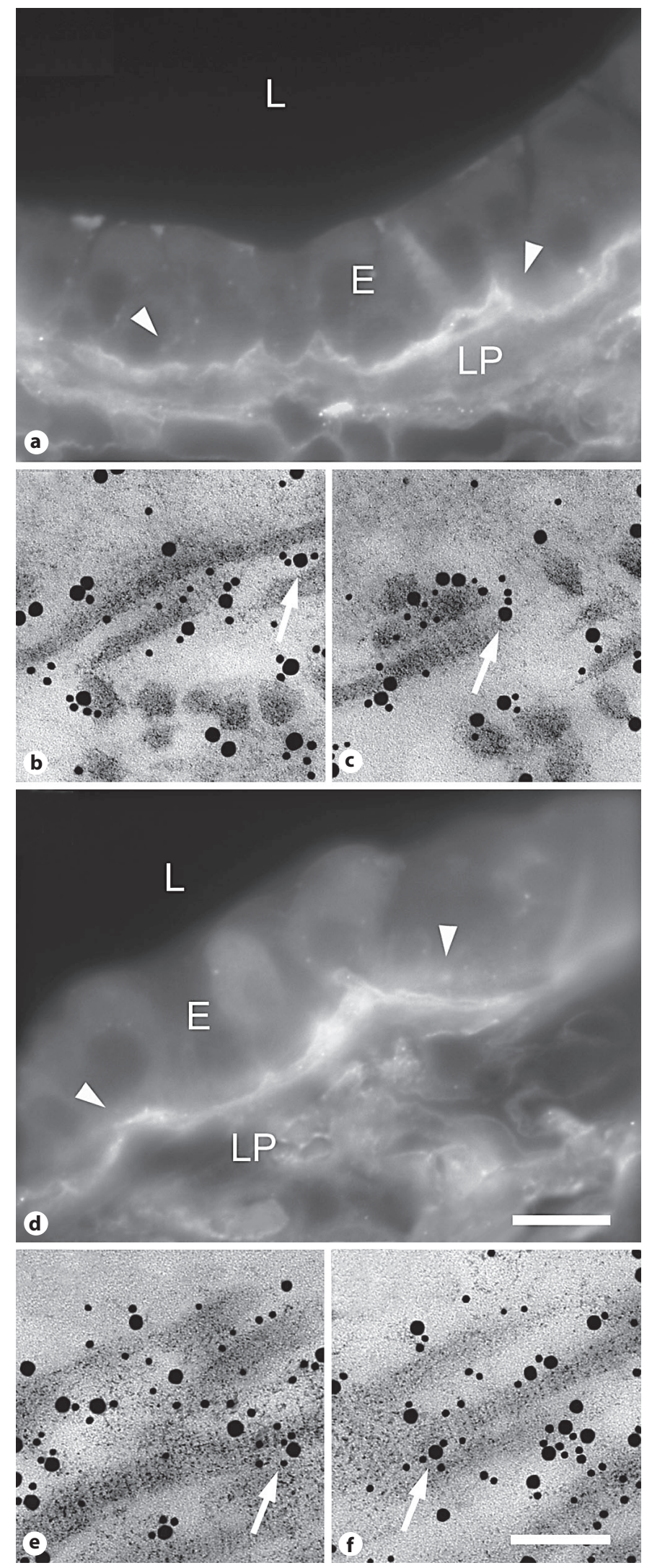


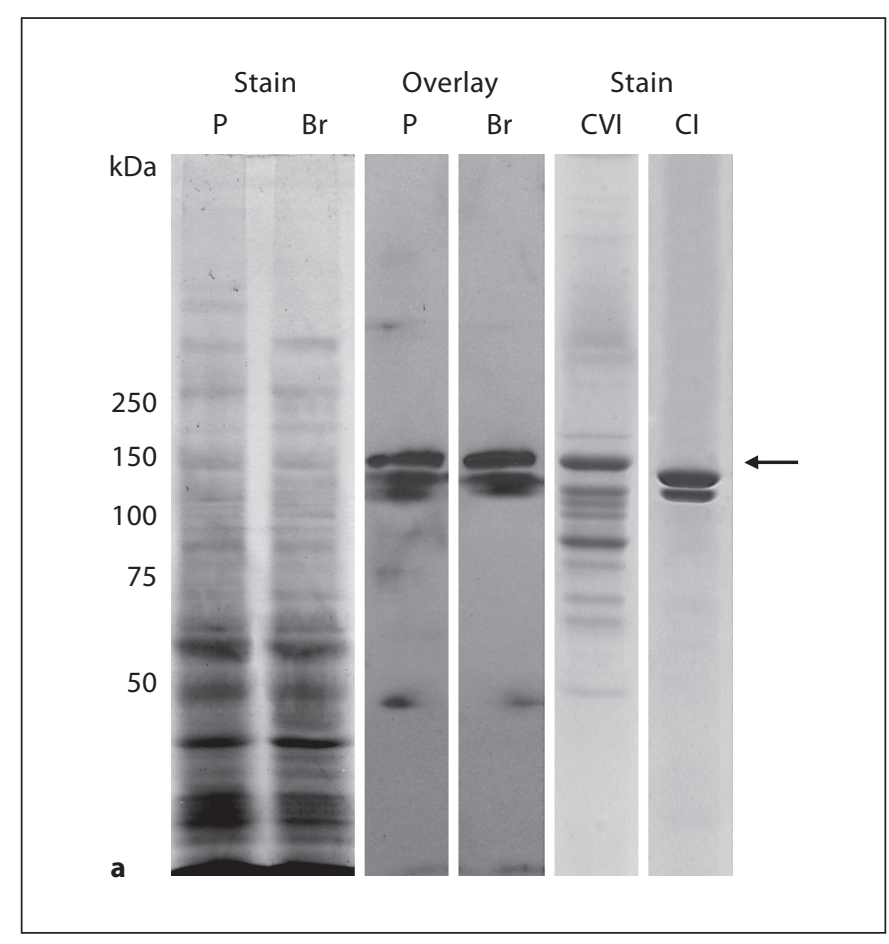

Fig. 2. Interaction of bacterial adhesins with collagen VI in vitro. a Extracts of murine pharynx $(\mathrm{P})$ and bronchus $(\mathrm{Br})$ were analyzed by reducing SDS-PAGE. One gel was stained with Coomassie Blue (stain) and the other was incubated with radiolabeled $\mathrm{CNBr}$ extracts from $S$. pyogenes (overlay, P) or S. pneumoniae (overlay, $\mathrm{Br}$ ). $\mathrm{M}_{\mathrm{r}}$ standards are indicated to the left. For comparison, the mobility of purified collagens I (stain, CI) and VI (stain,

S. pyogenes and S. pneumoniae Bind to Collagen VI in vitro

To identify airway matrix components serving as substrates for streptococci we performed ligand blot experiments (fig. 2a). Pharyngeal and bronchial samples were extracted with SDS, separated by SDS-PAGE and transferred to a PVDF membrane. Interestingly, radiolabeled CNBr extracts from S. pyogenes and S. pneumoniae bound to a few discrete bands of the larynx and bronchus extract, respectively, with apparent molecular masses in the range of 130 and $140 \mathrm{kDa}$ (fig. 2a, overlay). Comparison with the Coomassie stained collagen VI and I standards

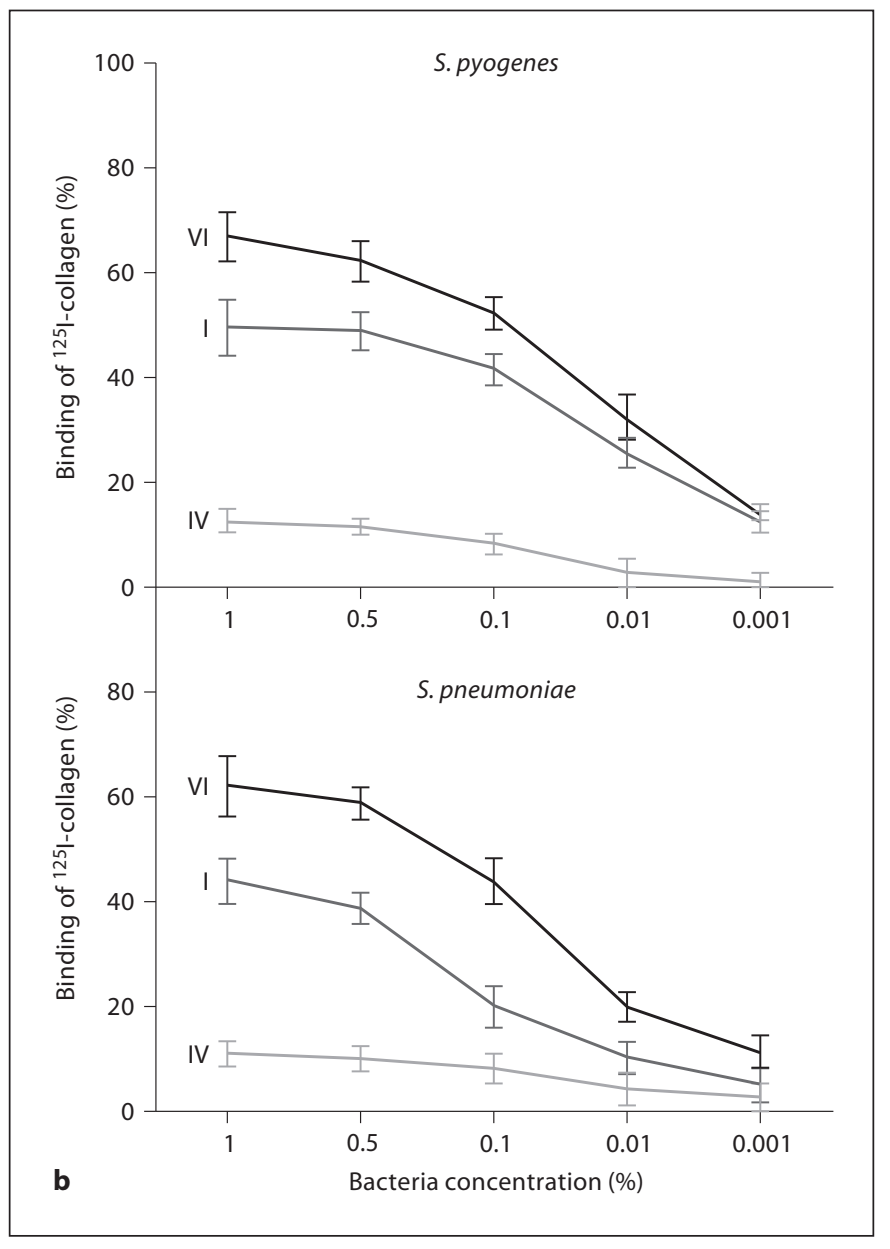

CVI) on reducing SDS-PAGE are shown to the right. The arrow points to the position of the collagen VI $\alpha 2$-chain at $140 \mathrm{kDa}$. b Titration of S. pyogenes and S. pneumoniae bacterial solutions with radiolabeled collagens I, IV and VI. Serial dilutions of bacteria were used: $1 \%\left(2 \times 10^{9} \mathrm{cfu} / \mathrm{ml}\right), 0.5 \%\left(1 \times 10^{9} \mathrm{cfu} / \mathrm{ml}\right), 0.1 \%$ $\left(2 \times 10^{8} \mathrm{cfu} / \mathrm{ml}\right), 0.01 \%\left(2 \times 10^{7} \mathrm{cfu} / \mathrm{ml}\right)$ and $0.001 \%\left(2 \times 10^{6}\right.$ $\mathrm{cfu} / \mathrm{ml})$.

(fig. 2a, stain, CVI and CI) showed that these bands exhibited a similar migration pattern as the $\alpha 2$-chain of collagen VI (arrow) and the $\alpha 1$ - and $\alpha 2$-chains of collagen I.

In another experimental setup, intact collagen VI microfibrils were purified from bovine cornea and radiolabeled with ${ }^{125}$ Iodine. Samples were added to bacterial suspensions, incubated and then centrifuged, followed by determining the relative amount of radioactivity bound to the bacterial pellet. The 2 examined pathogens strongly adsorbed collagen VI (fig. 2b). The collagen VI binding was compared to other collagens and turned out 

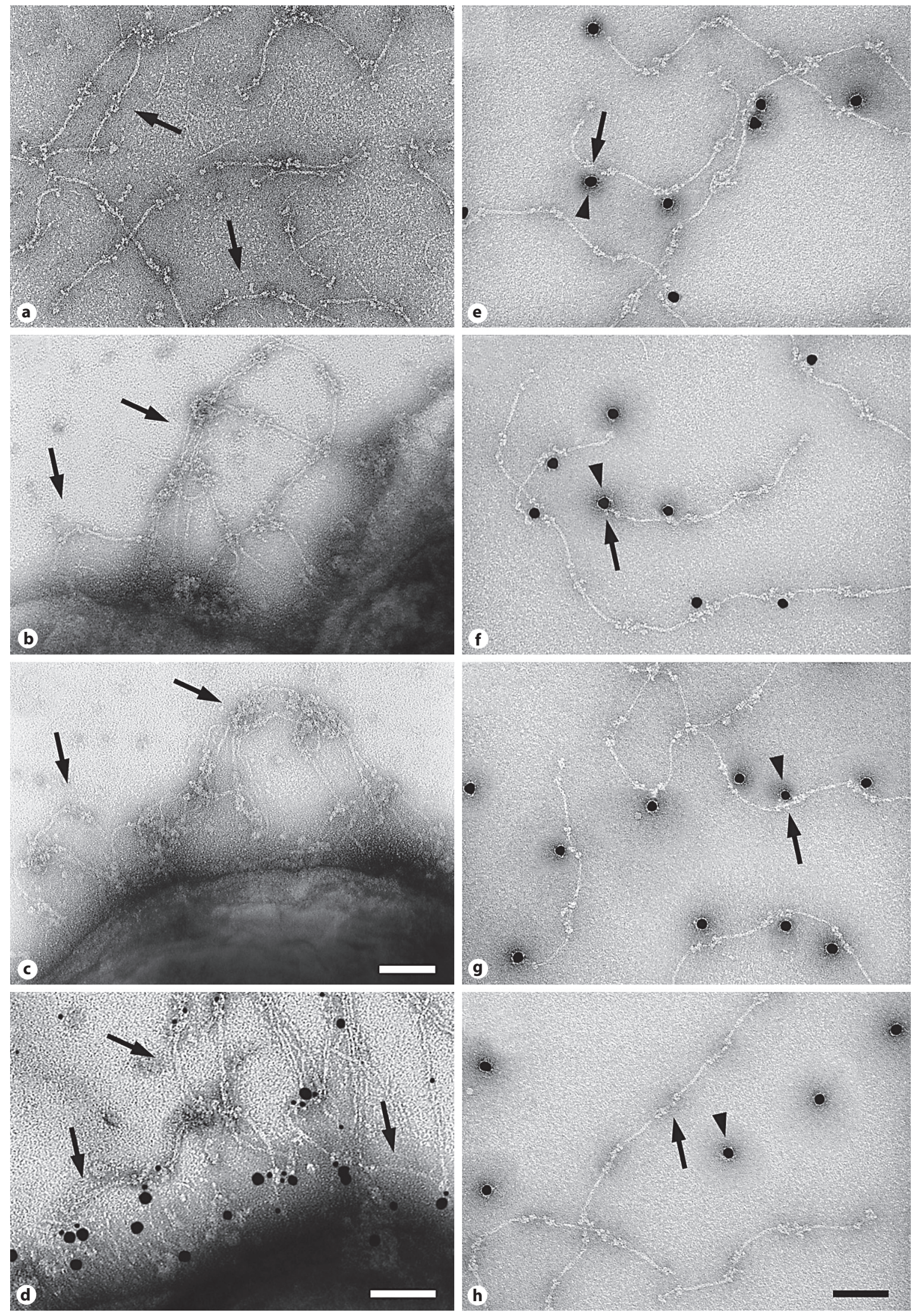
to be rather similar to the classical fibrillar collagen I. The basement membrane collagen IV showed much weaker affinity (fig. 2b). Taken together these data establish collagen VI as a relevant extracellular matrix target for streptococcal adhesion in the upper and lower airways.

S. pyogenes and S. pneumoniae Adhesins Recruit Collagen VI Microfibrils via Interactions with the Collagen Backbone Close to the Globular Domains

The in vitro observed adsorption of collagen VI to bacterial surfaces was examined in further detail by negative staining and transmission electron microscopy. This approach had the particular advantage that no protein modification with ${ }^{125}$ Iodine was necessary and intact collagen VI microfibrils could be used. Figure 3a shows purified microfibrils with the typical array of extended and globular protein domains. When such microfibrils were added to bacterial suspensions and examined in the microscope the surfaces of $S$. pneumoniae (fig. 3b) and S. pyogenes (fig. 3c) appeared densely covered with collagen VI networks (arrows). Furthermore, co-localization of gold-conjugated antibodies against collagen VI ( $5 \mathrm{~nm}$ gold) and M1 protein ( $15 \mathrm{~nm}$ gold), but not (data not shown) to the very similar M-like protein $\mathrm{H}$ [21] unraveled M1 protein as a novel collagen VI-binding adhesin of $S$. pyogenes (fig. 3d). In additional experiments, $\mathrm{CNBr}$ surface protein extracts were directly labeled with colloidal gold particles $(15 \mathrm{~nm})$ and added to collagen VI in vitro. Inspection by negative staining and electron microscopy revealed that gold conjugates (arrowheads) of both bacterial extracts bound close to the globular domains (arrows) on microfibrils (fig. 3e, f).

Fig. 3. Bacterial adhesins bind close to the globular domains of collagen VI microfibrils. Collagen VI microfibrils (arrows) were extracted and purified from bovine cornea (a) and allowed to react with S. pneumoniae (b) and S. pyogenes bacteria (c). Negative staining and electron microscopy visualizes collagen VI networks bound to the bacterial surface. Scale bar $=100 \mathrm{~nm}$. d Collagen VI (small gold) is co-localized with M1 protein (large gold) on the surface of $S$. pyogenes. Arrows point to individual microfibrils. Scale bar $=50 \mathrm{~nm}$. e, $\mathbf{f} \mathrm{CNBr}$ extracted surface proteins of $S$. pneumoniae and $S$. pyogenes, respectively, were conjugated with colloidal gold and bind close to the globular domains on collagen VI microfibrils. g Gold-labeled purified M1 protein from S. pyogenes binds to the same location on microfibrils, whereas protein $\mathrm{H}(\mathbf{h})$ does not seem to interact. Arrows point to the globular collagen VI protein domains and arrowheads to gold conjugates. Scale bar $=100 \mathrm{~nm}$.

Collagen VI is a Target for Respiratory Tract Pathogens
Similar interactions were observed for gold-labeled purified $\mathrm{M} 1$ protein (fig. 3g), but not for protein $\mathrm{H}$ (fig. 3h), confirming the novel role of $\mathrm{M} 1$ as a specific adhesin for collagen VI. Surface adhesins of S. pneumoniae with the capacity to recruit collagen VI microfibrils remain to be identified and characterized in further detail in future studies.

The airway epithelium is an important entry site for a number of human pathogens. Once bacteria have reached it colonization requires appropriate strategies to evade the various types of host response. Thus, initial microbial targeting to tissue ligands is a crucial step to avoid mechanical clearing by body fluids, to establish firm contact with the host and to facilitate spreading to other cells [9]. There are several bacterial surface structures that utilize epithelial cell surface molecules as ligands during colonization. For S. pyogenes M-proteins binding glycosaminoglycans and integrins, and for $S$. pneumoniae a fibronectin-binding protein, PavA, engaging integrins, have been described [for references see 22]. In this study we introduce collagen VI as an adhesive substrate for these pathogens. The presented data suggest that $S$. pyogenes and S. pneumoniae recruit collagen VI close to the N- and C-terminal globular domains via surface adhesins. Consequently, collagen VI microfibrils provide subepithelial adhesive matrices in vivo with multiple interaction sites where large numbers of pathogens can aggregate. This could imply a temporal and spatial sequence of events during the infection process where bacteria employ different ligands via different adhesins. Initially, bacteria may colonize the epithelium by adhering to epithelial cell surface ligands [22]. Subsequently, in the case of epithelial damage caused by epithelial shedding or by post viral infection injury, when the complex subepithelial matrix is exposed, they can move deeper into the host by utilizing collagen VI as an alternative substrate. Thus, collagen VI could be of particular importance during an invasive phase of infection.

\section{Acknowledgments}

This work was supported by grants from the Swedish Medical Research Council (projects 2008-7480, 2005-4791), the Foundations of Crafoord, Bergvall, Greta och Johan Kock, Alfred Österlund, Konung Gustav V:s 80-Årsfond, the Swedish Society for Medicine, and the Medical Faculty, Lund University. Maria Baumgarten is acknowledged for excellent technical assistance. Thanks to Rita Wallén and Eric Hallberg, Cell and Organism Biology, Lund University, for help with electron microscopy.

J Innate Immun 2010;2:160-166 


\section{References}

$>1$ Wilson R, Dowling RB, Jackson AD: The biology of bacterial colonization and invasion of the respiratory mucosa. Eur Respir J 1996; 9:1523-1530.

$>2$ Patti JM, Allen BL, McGavin MJ, Höök M: MSCRAMM-mediated adherence of microorganisms to host tissues. Annu Rev Microbiol 1994;48:585-617.

$>3$ de Bentzmann S, Tristan A, Etienne J, Brousse N, Vandenesch F, Lina G: Staphylococcus aureus isolates associated with necrotizing pneumonia bind to basement membrane type I and IV collagens and laminin. J Infect Dis 2004;190:1506-1515.

4 Kostrzynska M, Wadström T: Binding of laminin, type IV collagen, and vitronectin by Streptococcus pneumoniae. Zentralbl Bakteriol 1992;277:80-83.

5 Selvarangan R, Goluszko P, Singhal J, Carnoy C, Moseley S, Hudson B, Nowicki S, Nowicki B: Interaction of Dr adhesin with collagen type IV is a critical step in Escherichia coli renal persistence. Infect Immun 2004; 72:4827-4835.

6 Fink DL, Green BA, St Geme JW 3rd: The Haemophilus influenzae Hap autotransporter binds to fibronectin, laminin, and collagen IV. Infect Immun 2002;70:4902-4907.

7 Gelse K, Poschl E, Aigner T: Collagens: structure, function, and biosynthesis. Adv Drug Deliv Rev 2003;55:1531-1546.
$>8$ Xu Y, Rivas JM, Brown EL, Liang X, Höök M: Virulence potential of the staphylococcal adhesin CNA in experimental arthritis is determined by its affinity for collagen. J Infect Dis 2004;189:2323-2333.

9 Dinkla K, Rohde M, Jansen WT, Kaplan EL, Chhatwal GS, Talay SR: Rheumatic fever-associated Streptococcus pyogenes isolates aggregate collagen. J Clin Invest 2003;111: 1905-1912.

10 Bruns RR, Press W, Engvall E, Timpl R, Gross J: Type VI collagen in extracellular, $100-\mathrm{nm}$ periodic filaments and fibrils: identification by immunoelectron microscopy. J Cell Biol 1986;103:393-404.

11 Brown JC, Timpl R: The collagen superfamily. Int Arch Allergy Immunol 1995;107: 484-490.

12 Malmström J, Tufvesson E, Löfdahl CG, Hansson L, Marko-Varga G, WestergrenThorsson G: Activation of platelet-derived growth factor pathway in human asthmatic pulmonary-derived mesenchymal cells Electrophoresis 2003;24:276-285.

13 Specks U, Nerlich A, Colby TV, Wiest I, Timp, R: Increased expression of type VI collagen in lung fibrosis. Am J Respir Crit Care Med 1995;151:1956-1964.

14 Cunningham MW: Pathogenesis of group A streptococcal infections. Clin Microbiol Rev 2000;13:470-511.

-15 Bridy-Pappas AE, Margolis MB, Center KJ, Isaacman DJ: Streptococcus pneumoniae: description of the pathogen, disease epidemiology, treatment, and prevention. Pharmacotherapy 2005;25:1193-1212.
16 Spissinger T, Engel J: Type VI collagen beaded microfibrils from bovine cornea depolymerize at acidic $\mathrm{pH}$, and depolymerization and polymerization are not influenced by hyaluronan. Matrix Biol 1995;14:499-505.

17 Wiberg C, Klatt AR, Wagener R, Paulsson M, Bateman JF, Heinegård D, Mörgelin M: Complexes of matrilin-1 and biglycan or decorin connect collagen VI microfibrils to both collagen II and aggrecan. J Biol Chem 2003;278:37698-37704.

18 Otten RA, Raeder R, Heath DG, Lottenberg $\mathrm{R}$, Cleary PP, Boyle MD: Identification of two type IIa IgG-binding proteins expressed by a single group A Streptococcus. J Immunol 1992;148:3174-3182.

19 Carlemalm E: Lowicryl resins in microbiology. J Struct Biol 1990;104:189-191.

20 Bengtson SH, Eddleston J, Mörgelin M, Zuraw BL, Herwald H: Regulation of kinin $\mathrm{B}(2)$ receptors by bradykinin in human lung cells. Biol Chem 2008;389:1435-1440.

-21 Åkesson P, Cooney J, Kishimoto F, Björck L: Protein H: a novel IgG binding bacterial protein. Mol Immunol 1990;27:523-531.

22 Ulanova M, Gravelle S, Barnes R: The role of epithelial integrin receptors in recognition of pulmonary pathogens. J Innate Immun 2009; 1:4-17. 